\title{
Dehydroacetic acid Derived Schiff base as Selective and Sensitive Colorimetric Chemosensor for the Detection of $\mathrm{Cu}$ (II) ions in Aqueous Medium
}

Devika Vashisht ${ }^{\mathrm{a}}$, Shikha Sharma ${ }^{\mathrm{a}}$, Rakesh Kumar ${ }^{\mathrm{a}}$, Vaneet Saini ${ }^{\mathrm{a}}$, Vikram Saini ${ }^{\mathrm{b}}$, Alex Ibhadon $^{\mathrm{c}}$, Subash Chandra Sahoo ${ }^{\mathrm{a}}$, Shweta Sharma ${ }^{\mathrm{d}}$, S. K. Mehta ${ }^{\mathrm{a} *}$ and Ramesh Kataria ${ }^{\text {a* }}$

${ }^{a}$ Department of Chemistry and Centre of Advanced Studies in Chemistry Panjab University, Chandigarh 160014, India

${ }^{\mathrm{b}}$ Department of Biotechnology, All India Institute of Medical Sciences (AIIMS), New Delhi, Delhi-110029, India

${ }^{\mathrm{c}}$ Department of Chemical Engineering, University of Hull, Hull HU6 7RX, United Kingdom

${ }^{\mathrm{d}}$ Institute of Forensic Science and Criminology, Panjab University, Chandigarh 160014, India

Corresponding Email: skmehta@pu.ac.in, rkataria@pu.ac.in

\begin{abstract}
The deficiency, as well as overconsumption of essential metal ions, has serious health implications. Hence, the design and synthesis of sensors for accurate detection of such ionic species are of great significance. We report the synthesis and characterization of a yellowcoloured Dehydroacetic acid-based chemosensor DHB ((E)-N-(1-(2-hydroxy-6-methyl-4-oxo4H-pyran-3-yl) ethylidene) benzohydrazide for a quick and affordable copper detection. A naked-eye visible colour transition from light yellowish to bluish green was observed instantly following $\mathrm{Cu}^{2+}$ addition. DHB did not yield colour change with any other ionic species indicating its specificity. The binding of DHB to $\mathrm{Cu}^{2+}$ caused a blue shift accompanied by an increased intensity due to an intramolecular charge transfer (ICT). No interference from competitive ionic species reiterated the selectivity of this probe. The outcomes of single-crystal X-ray analysis, titration studies, and Job's plot indicated a 1:2 stoichiometry between $\mathrm{Cu}^{2+}$ and DHB. The experimental results matched well with the theoretical results obtained from Density Functional Theory (DFT) calculations. The practical applicability of the probe for $\mathrm{Cu}^{2+}$ estimation was further determined using water samples from various sources. The sensor could detect copper as low as $0.156 \mu \mathrm{M}$ in an aqueous media which is very less than the permissible value of $20 \mu \mathrm{M}$ in water.
\end{abstract}




\section{Keywords}

2 Colorimetric detection; Cu(II); Schiff's base; Chemosensor; Dehydroacetic Acid

\section{1. Introduction}

4 The sensing technology has evolved significantly to develop well-equipped molecular sensors to monitor biologically and environmentally important metal ions [1]. Metals are natural ingredients of the Earth's crust. Natural and man-made activities cause their discharge into the environment. These metal ions enter the complex biological systems following different pathways like food, air, drinking water, etc. and subsequently lead to bioaccumulation over a period of time [2]. Although metal ions are crucial for the growth and development of complex biological systems [3], however, their over-consumption may cause serious side-effects and hence metal levels in food/water needs to be monitored.

The fabrication and implementation of colorimetric chemosensors for the detection of such ionic species is a better option than the sophisticated and complicated conventional instrumentations $[4,5]$. The conventional instrumentation techniques available for detection of the metallic species involve time-consuming pre-sample treatment, complex experimentation and sophisticated handling, which limits their routine application. In contrast, chemosensors have come out as superior alternatives due to their cost-effectiveness, and easy operation $[6,7]$.

A chemosensor is a chemical system which has the ability to bind with a specific target analyte causing an alteration in one or more assets of the system in the form of colour, fluorescence or redox potentials [8]. The advances in the synthesis of chemosensors for tagging biologically and environmentally essential ions has received spotlight because of their significant roles in industry, living systems, photo-sensitization, drug development, environmental monitoring, cancer detection and human health [9,10]. Among different chemosensors, colorimetric chemosensors are easy to apply as they allow detection of a specific target by inducing a colour change and do not require complicated pre-sample preparation [4,8,11-13]. Schiff's bases form one class of the different colorimetric chemosensors which are used for signaling and monitoring the ionic species in an aqueous medium. They have a capability to bind to a specific target through imine nitrogen and stabilize the target species depending upon the signature size of the cavity and target ionic species. Schiff's bases are also known for antibacterial, anti-tuberculosis, anti-carcinogenic properties, etc. [14]. Several Schiff base entities have been reported and used for the fluorometric and colorimetric detection of metal ions 
1 specifically $\mathrm{Cu}^{2+}$ [15-19]. Copper $(\mathrm{Cu})$ is the third most common transition element (after Iron 2 and Zinc) in the human body with prescribed consumption limits [20, 21]. US Environmental 3 Protection Agency (EPA) has set $20 \mu \mathrm{M}$ of copper in drinking water as the upper limit [22-24]. 4 Copper is essential for maintaining healthy metabolism in humans [25]. The deficiency of copper can lead to myeloneuropathy, fatigue, weak and brittle bones, pale skin and while the exceeding exposure to copper can trigger neurodegenerative disorders, renal damage, and oxidative stress. Inadequate levels of copper can cause Wilson's and Alzheimer's disease [15-18, 26].

Yang et al. [27], Mergu et al. [28] Manhanshi et al. [29], Razak et al. [30], Mohammadi et al. [31] and Manna et al. [32] synthesized diphenyl-derived salicylhydrazone Schiff's base, (E)N'-((7-(diethylamino)-2-oxo-2H-chromen-3-yl)methylene)-3,4,5-trimethoxybenzohydrazide, 1N-allyl-2-(2, 5-dimethoxyphenyl)-4, 5-diphenyl-1H-imidazole, Chromone-based colorimetric sensor, bis-thiourea (BT) ligand compound, N,N'-(((3,3'-dimethoxy-[1,1'-biphenyl]-4,4'diyl)bis(azanediyl))bis(carbonothioyl))bis(4-methoxybenzamide) based microspheres and N-(2hydroxybenzylidene)-2-(benzamido) benzohydrazide which were used for the sensing of $\mathrm{Cu}^{2+}$. However, these ligands offer many disadvantages including a higher ratio of organic solvents in the solvent system and limit of detection. The objective of the present work was to synthesize modified Schiff base DHB ((E)-N-(1-(2-hydroxy-6-methyl-4-oxo-4H-pyran-3-yl) ethylidene) benzohyrazide) by setting a condensation reaction between benzohydrazide and DHA. The chemosensor DHB was used for the purpose of sensing $\mathrm{Cu}^{2+}$, to achieve lower detection limit and naked eye visible detection without much use of organic solvent. The proposed chemosensor DHB could detect copper as low as $0.156 \mu \mathrm{M}$ in an aqueous medium which is very less than the prescribed value of $20 \mu \mathrm{M}$ set by US EPA.

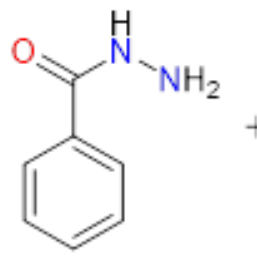

Benzohydrazide<smiles>CC(=O)c1c(O)oc(C)cc1=O</smiles>

DHA<smiles>CC(=NNC(=O)c1ccccc1)c1c(O)oc(C)cc1=O</smiles>

DHB 


\section{2. Experimental}

2 2.1. Materials

3 Ethyl benzoate, hydrazine hydrate, and Dehydroacetic acid (DHA) were bought from 4 commercial supplier Sigma Aldrich and were used without further purification. Ethanol was

5 ordered from Changsu Yanguan Chemicals. The solution of all the cations $\left(\mathrm{Ce}^{3+}, \mathrm{Pb}^{2+}, \mathrm{Hg}^{+}, \mathrm{Cd}^{2+}\right.$, $6 \mathrm{Ag}^{+}, \mathrm{Pd}^{2+}, \mathrm{Zn}^{2+}, \mathrm{Cu}^{2+}, \mathrm{Ni}^{2+}, \mathrm{Co}^{2+}, \mathrm{Mn}^{2+}, \mathrm{Fe}^{2+}, \mathrm{Cr}^{3+}, \mathrm{Ca}^{2+}, \mathrm{K}^{+}, \mathrm{Na}^{+}$) were made by dissolving their 7 nitrates and acetates in double-distilled water. Metallic salts were purchased from Alfa-Aesar. 8 The buffer solutions were made using 4-(2-hydroxyethyl)-1-piperazineethanesulfonic acid 9 (HEPES) procured from Avra Synthesis. $\mathrm{pH}$ studies were performed by using an appropriate amount of sodium hydroxide and hydrochloric acid. All the glassware was washed using aqua regia.

\subsection{Instrumentation}

Fourier Transform Infrared (FT-IR) spectra were logged on Thermo Scientific Nicolet iS-50 spectrometer in the range $4000-400 \mathrm{~cm}^{-1}$. A $10 \mathrm{~mm}$ path length quartz cuvette was used to record UV-vis spectra in the wavelength range 200-800 nm on a Perkin Elmer Lambda 750 UV/Vis/NIR spectrophotometer. ${ }^{1} \mathrm{H}-\mathrm{NMR}$ of the synthesized probe DHB in deuterated Trichloromethane $\left(\mathrm{CDCl}_{3}\right)$ as a solvent was recorded on Bruker DRX spectrometer using (TMS) trimethylsilane as an internal reference. The $\mathrm{pH}$ values were noted down using calibrated Cole Parmer P200 benchtop digital $\mathrm{pH}$ meter.

\subsection{Method}

The colorimetric chemosensor (Scheme1) DHB ((E)-N-(1-(2-hydroxy-6-methyl-4-oxo-4Hpyran-3-yl) ethylidene) benzohyrazide) was synthesized according to the reported method [30] by setting a one-pot condensation reaction between benzohydrazide and DHA. For the synthesis of benzohydrazide, hydrazine hydrate was added to the ethanolic solution of ethyl benzoate followed by refluxing at $60{ }^{\circ} \mathrm{C}$. The precipitates were obtained after $7 \mathrm{~h}$ of reflux. The white compound was carefully filtered, washed several times with ethanol and finally dried in a vacuum desiccator. For the synthesis of DHB, DHA was added to an ethanolic solution of benzohydrazide and the solution was stirred for $24 \mathrm{~h}$ at room temperature. The yellow product was obtained, filtered and dried in a vacuum desiccator. The DHB is completely solvable in solvents like methanol, ethanol, chloroform, dimethyl sulphoxide (DMSO) and dimethyl formamide (DMF). 


\section{2.4. Crystallography studies}

2 Crystal of $\mathrm{Cu}(\mathrm{II})$-DHB was mounted on Hampton Cryo-loop. The geometric and intensities data for the crystals was collected using a Super-Nova (Mo) X-ray diffractometer equipped with a micro-focus sealed X-ray tube Mo-K $\alpha(\lambda=0.71073 \AA)$ X-ray source and HyPix3000 (CCD plate) detector of with increasing $\omega$ (width of 0.3 per frame) at a scan speed of either 5 or $10 \mathrm{~s} /$ frame. All the data were collected at room temperature. Data acquisition and extraction were done using the CrysAlisPro software. Using Olex2 [34], the structure was solved with the SIR2004 [35] structure solution program using Direct Methods and refined with the ShelXL [36] refinement package using Least Squares minimization. All non-hydrogen atoms were refined with anisotropic thermal parameters.

\subsection{Selective Cation Recognition Studies}

DHB was found to be soluble in a solvent system comprised of 80 parts of distilled water and 20 parts of ethanol. The metal ion sensibility was checked by additional dilution of $1 \mathrm{mM}$ stock solution of DHB prepared in solvent system viz 80:20 distilled water: ethanol. The cation recognition experiment was conducted by addition of $0.75 \mu \mathrm{M}$ of each metal salt solution to 10 $\mu \mathrm{M}$ of detector DHB. The difference in the spectral behaviour was observed using UV-vis spectroscopy. All the solutions prepared were left as such for nearly 15 minutes to allow complete complexation of DHB with cationic species.

\section{6. pH Studies}

To evaluate the effect of $\mathrm{pH}$ on sensing capability of $\mathrm{DHB}$, a range of solutions with $\mathrm{pH} 2-11$ was prepared by using HEPES buffer. An appropriate amount of sodium hydroxide/hydrochloric acid was added to regulate the $\mathrm{pH}$. A $1 \mathrm{mM}$ stock solution of DHB was prepared by dissolving it in 80:20 distilled water: ethanol. A $0.1 \mathrm{ml}$ aliquot from the stock solution of DHB was added to $5 \mu \mathrm{M}$ of $\mathrm{Cu}^{2+}$ prepared in HEPES buffer and scanned using UV-vis spectroscopy. HEPES buffer was selected because of its negligible binding ability with metal ions. Also, the HEPES buffer does not absorb in UV-vis range which makes it suitable for the proposed system [37-39].

\subsection{Titration Studies}

Although the probe could sense the $\mathrm{Cu}^{2+}$ at the original $\mathrm{pH}$, the best performance was found at $\mathrm{pH}=6$ which is quite close to neutral $\mathrm{pH}$. The titration studies were done at optimized $\mathrm{pH}=6$ and the absorption trend with a change in concentration was observed. A range of solutions with 
$1 \mathrm{Cu}^{2+}$ concentration from 0.24 to $3.5 \mu \mathrm{M}$ in HEPES buffer using $10 \mu \mathrm{M}$ of DHB were made and

2 scanned using UV-vis spectroscopy.

3 2.8. Real samples of water

4 For the real-time applicability of the chemosensor, various samples like distilled water, drinking

5 water, sea-water, and river water were collected and spiked with a known concentration of $\mathrm{Cu}^{2+}$.

6 Sea water was taken from the Arabian Sea (Mumbai, India) and River water from the Saraswati

7 River (Haryana, India). All the real water samples were filtered to remove solid impurities using

8 Whatman filter paper. The drinking water sample was collected from the domestic water supply.

\subsection{Computational Studies}

The input files of $\mathrm{Cu}(\mathrm{II})-\mathrm{DHB}$ complex and DHB were organized using GaussView 6.0.16. All the computational calculations were performed on Gaussian 09 rev. D.01 using DFT method. The optimized minimum energy structures were obtained by using exchange-correlation functional B3LYP/GEN and 6-31G (d,p) basis set for N, O, C, H atoms and LANL2DZ basis set for Copper atom in the gas phase. GEN keyword combined 6-31G (d,p) and LANL2DZ basis sets. Evident from the analysis of vibrational frequencies, the optimized structures of organic moieties were found to be stationary points corresponding to local minima without imaginary frequencies.

\section{Results and Discussion}

The UV-vis absorption plot (Figure 1) of yellow-coloured product DHB exhibited an absorption band around $260 \mathrm{~nm}$ attributed to the $\pi \rightarrow \pi *$ transitions of the aromatic ring. The $n \rightarrow \pi *$ transitions of less energy from the lone pair of $\mathrm{N}$ in $\mathrm{C}=\mathrm{N}$ bond to the $\pi$ bond of the aromatic ring were accountable for the band centred at 360 $\mathrm{nm}$. The FT-IR spectrum of the receptor

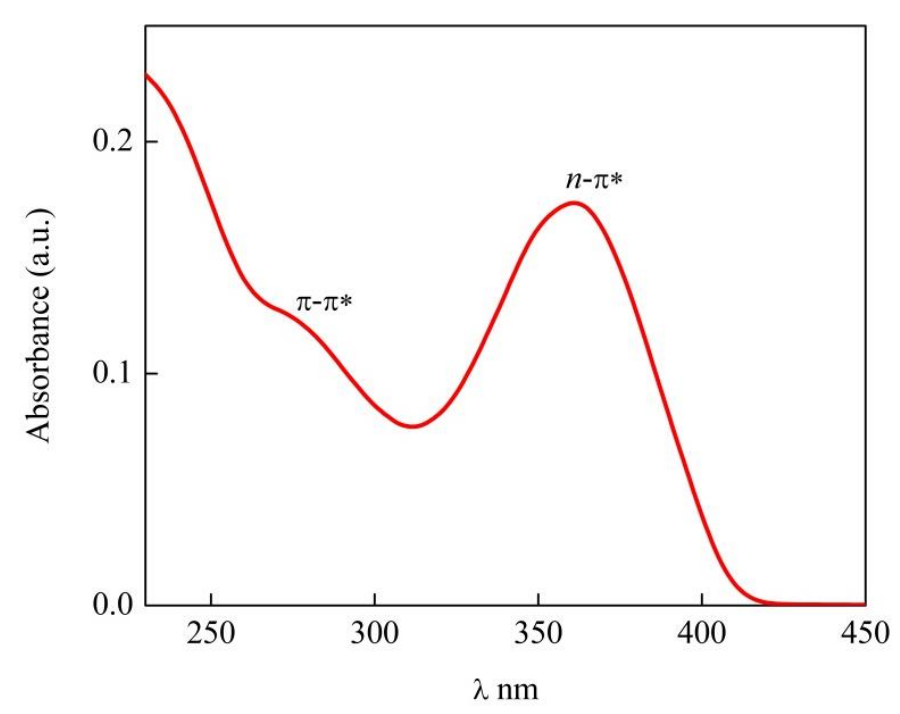

Figure 1. UV-vis spectrum of the synthesized probe DHB DHB revealed a peak at $1643 \mathrm{~cm}^{-1}$ ascribed to imine $\mathrm{C}=\mathrm{NH}$ of the receptor.

The sharp peak located at $8.45 \mathrm{ppm}$ of the ${ }^{1} \mathrm{H}-\mathrm{NMR}$ spectra of the DHB signified the successful creation of azomethnic $\mathrm{C}=\mathrm{NH}$ bond in the receptor (Figure $\mathrm{S} 1$ ). 


\begin{tabular}{|l|l|l|l|}
\hline Compound & IR stretching $\left(\mathbf{c m}^{-1}\right)$ & UV-vis absorption peak $(\mathbf{n m})$ & ${ }^{\mathbf{1}}$ H-NMR $(\mathbf{p p m})$ \\
\hline DHB & $1643\left(v_{\mathrm{C}=\mathrm{N}}\right)$ & $\lambda_{\text {abs }}=260\left(\pi \rightarrow \pi^{*}\right)$ & $7.1-8($ aromatic $\mathrm{H})$ \\
& $1656\left(v_{\mathrm{C}=\mathrm{O})}\right.$ & $\lambda_{\text {abs }}=360\left(n \rightarrow \pi^{*}\right)$ & $8.5(\mathrm{C}=\mathrm{NH})$ \\
\hline
\end{tabular}

\section{3.1. Cation selectivity studies}

3 The performance of the receptor DHB was probed after addition of various cationic species such

4 as $\mathrm{Ag}^{+}, \mathrm{Hg}^{2+}, \mathrm{Ni}^{2+}, \mathrm{Ba}^{2+}, \mathrm{Pb}^{2+}, \mathrm{Na}^{+}, \mathrm{Mn}^{2+}, \mathrm{Mg}^{2+}, \mathrm{Al}^{3+}, \mathrm{Ca}^{2+}, \mathrm{K}^{+}, \mathrm{Fe}^{2+}, \mathrm{Zn}^{2+}, \mathrm{Cr}^{3+}, \mathrm{Co}^{2+}, \mathrm{Ce}^{3+}$,

$5 \mathrm{Cd}^{2+}, \mathrm{Cu}^{2+}$, and $\mathrm{Fe}^{3+}($ Figure 2$)$

6 Modification of optical

7 behaviour in terms of drastic

8 change in the colour of DHB on

9 the addition of $\mathrm{Cu}^{2+}$ from

10 colourless to bluish green colour was observed which gave the confirmation of its complexation (Figure 3). A blue shift in the UV-vis absorption spectrum of DHB upon addition of $\mathrm{Cu}^{2+}$ substantiated the complexation with the DHB.

No noteworthy change was seen after the addition of an equimolar solution of other cationic species. The instant colour change of the solution containing DHB following the addition of $\mathrm{Cu}^{2+}$ highlighted its suitability for real-time analysis.

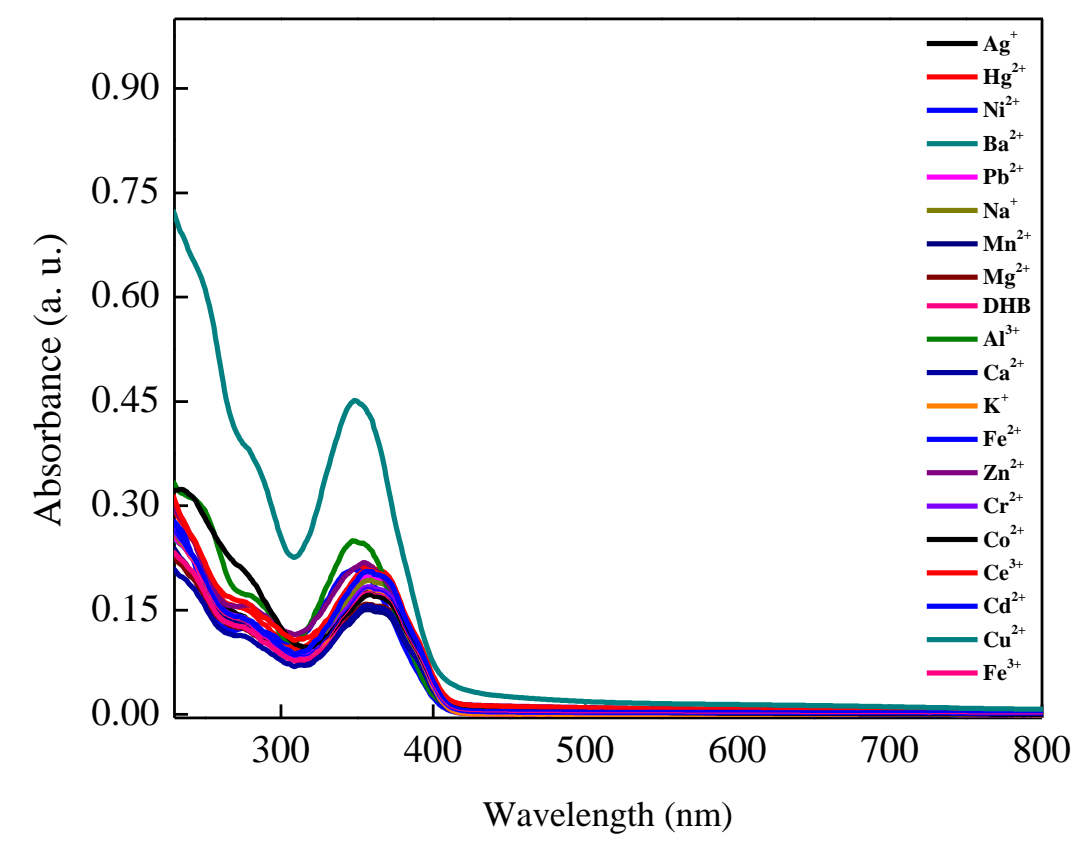

Figure 2. Absorption spectral changes of DHB $(10 \mu \mathrm{M})$ after the addition of equimolar concentrations of various cations

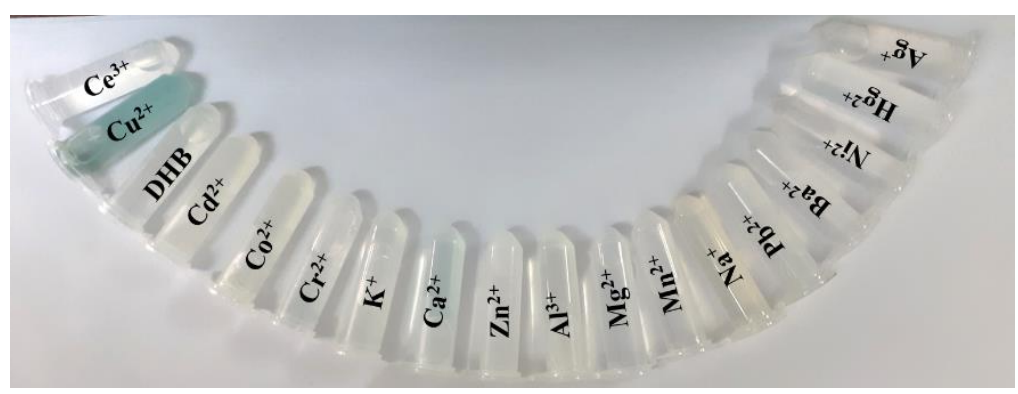

Figure 3. Naked eye visible colour changes induced in DHB (ethanol: water in 8:2 v/v) after equimolar addition of different metal ions $(20 \mu \mathrm{M})$

\subsection{FT-IR investigation}

The FT-IR spectrum of the fabricated probe DHB (Figure 4) exhibited a strong azomethinic vibration around $1643 \mathrm{~cm}^{-1}$. After complexation with $\mathrm{Cu}^{2+}$, the azomethinic stretching vibration 
1 shifted to $1617 \mathrm{~cm}^{-1}$. The

2 vibrations due to lactonic $\mathrm{C}=\mathrm{O}$ of

3 the group of DHB drifted from

$4 \quad 1656 \mathrm{~cm}^{-1}$ to $1673 \mathrm{~cm}^{-1}$ in $\mathrm{Cu}(\mathrm{II})$ -

5 DHB [40]. The N-H stretching

6 vibrations were visible at 3104

$7 \mathrm{~cm}^{-1}$. The signals around $1437 \&$

$8677 \mathrm{~cm}^{-1}$ were due to $\mathrm{O}-\mathrm{H}$ in-

9 plane and out plane bending of

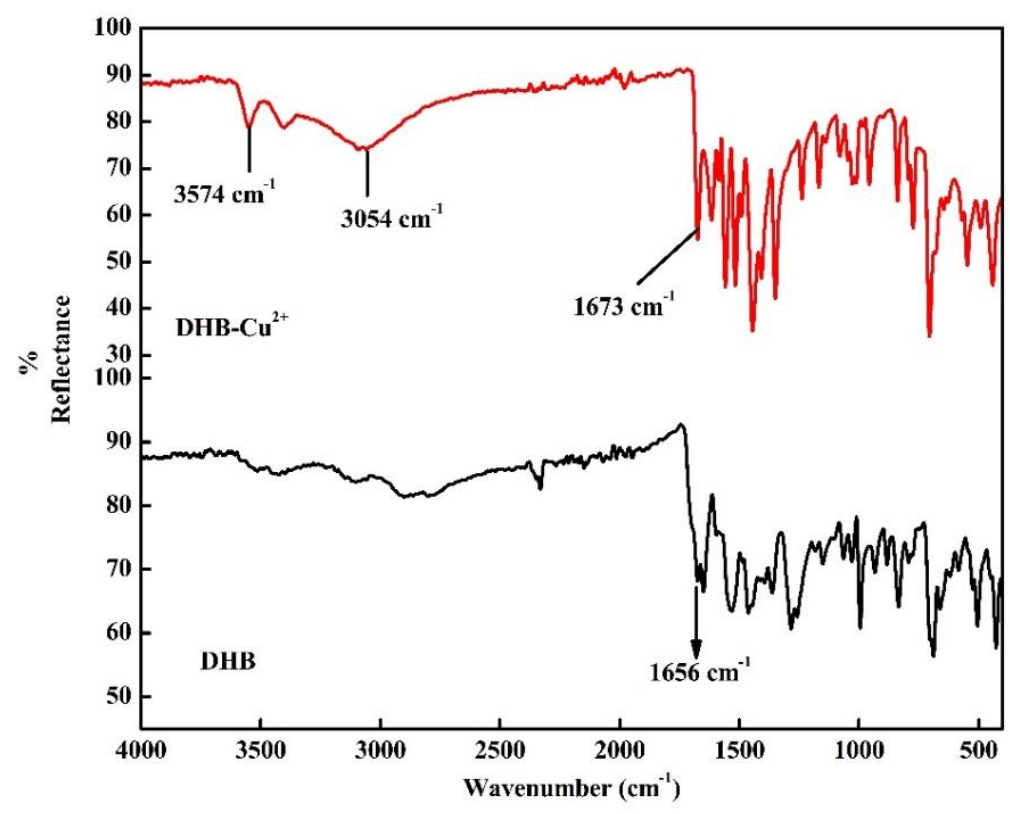

Figure 4. FT-IR spectrum of DHB and its $\mathrm{Cu}^{2+}$ complex spectrum exhibited $v_{\mathrm{C}-\mathrm{O}}$ stretching in $1130-1300 \mathrm{~cm}^{-1}$ range which is due to phenolic $\mathrm{C}-\mathrm{O}$ stretching. In $\mathrm{Cu}(\mathrm{II})-\mathrm{DHB}, \mathrm{Cu}-$ $\mathrm{O}$ and $\mathrm{Cu}-\mathrm{N}$ stretching signals appeared at $535 \mathrm{~cm}^{-1}$ and $660 \mathrm{~cm}^{-1}$, respectively [41]. The signal in the range $3200-3400 \mathrm{~cm}^{-1}$ broadened due to extensive hydrogen bonding. The $\mathrm{C}=\mathrm{N}$ stretch shifted to $1617 \mathrm{~cm}^{-1}$ after complexation with $\mathrm{Cu}^{2+}$. A drastic variation in the $\mathrm{C}=\mathrm{O}$ and $\mathrm{C}=\mathrm{N}$ stretch suggested coordination through $\mathrm{C}=\mathrm{O}$ and $\mathrm{C}=\mathrm{N}$.

\subsection{Crystal Structure}

Addition of DHB to the solution of $\mathrm{Cu}^{2+}$ transformed the solution from colourless to green. The observed change was due to the formation of $\mathrm{Cu}(\mathrm{II})$-DHB complex between the receptor and the target ion in ethanol and water (2:8) mix ture. The complex $\mathrm{Cu}$ (II)-DHB crystalized in the triclinic system with $P-1$ space group. The asymmetric unit contained one $\mathrm{Cu}$-metal centre and two ligands and a coordinated water molecule. The $\mathrm{Cu}$-center adopted a distorted square pyramidal geometry where one of the ligands coordinated to the metal in a tridentated fashion via ONO coordination pocket (Figure 5). The crystallographic parameters are shown in table S1. The fourth position was engaged with a water molecule in the equatorial plane while the apical fifth position was occupied by the O-atom of the DHB moiety of another ligand with a bond distance of $3.621 \AA$ which is common for the $\mathrm{Cu}$-square pyramidal system. The equatorial $\mathrm{Cu}-\mathrm{O}$ bond lengths were within the range of $1.8821(15)-1.9813(16)$ and that of $\mathrm{Cu}-\mathrm{N}$ of $1.9144(18) \AA$.

The water molecule positioned in equatorial place, H-bonded via both inter and intramolecular mode with a distance of 2.776 and $2.788 \AA$ with O-atoms of amide and DHA molecule 
respectively. The protonated -NH-NH group was H-bonded with O-atoms of DHA moiety of the coordinated ligand.
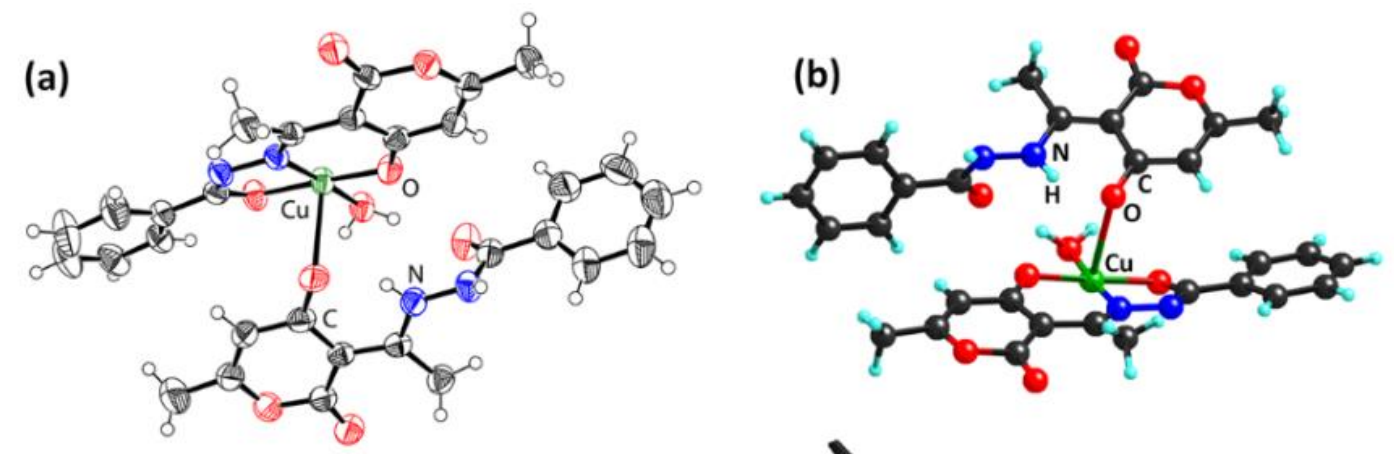

(c)

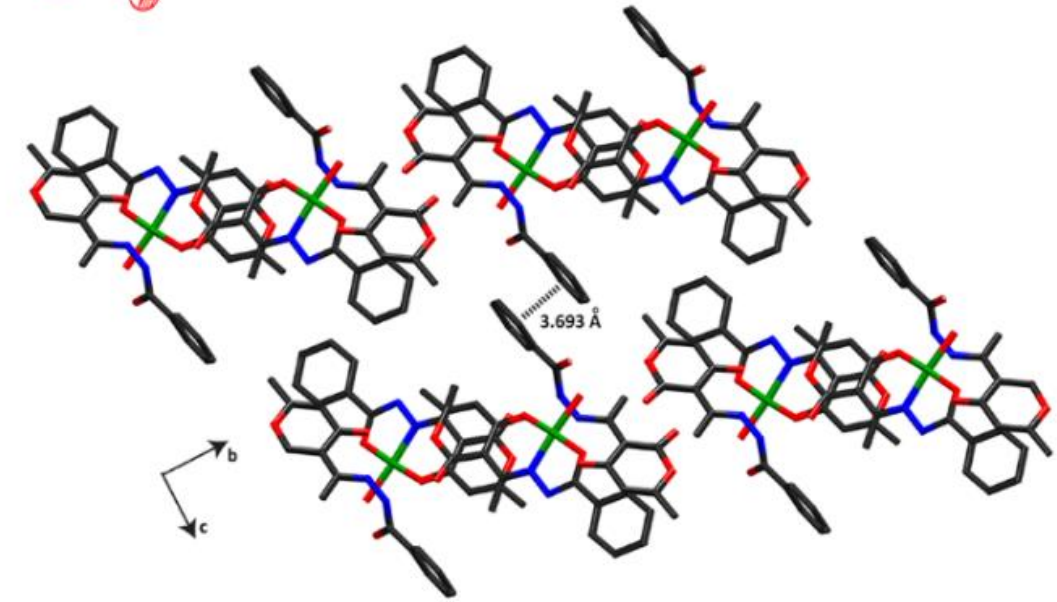

Figure 5. (a) Ortep diagram of $\mathrm{Cu}(\mathrm{II})$-DHB with $30 \%$ thermal ellipsoid; (b) Optimized structure of $\mathrm{Cu}$ (II)DHB; (c) Lattice picture of the molecule along ac-plane showing a 1D chain of molecules formed due to various H-bonds

A 1D chain of molecules thus formed due to various H-bonds along $a c$-plane and the list is given in the table S2. In the $b c$-plane, clear $\pi-\pi$ interaction formed between the aromatic groups of two adjacent the complexes with a distance of 3.693 $\AA$ (Figure 5c) was observed, resulting in a layer like an arrangement. Both the $\mathrm{N}$-atoms of the partially coordinated ligand were protonated leaving the hydroxide $\mathrm{O}$ atom to coordinate with metal. The

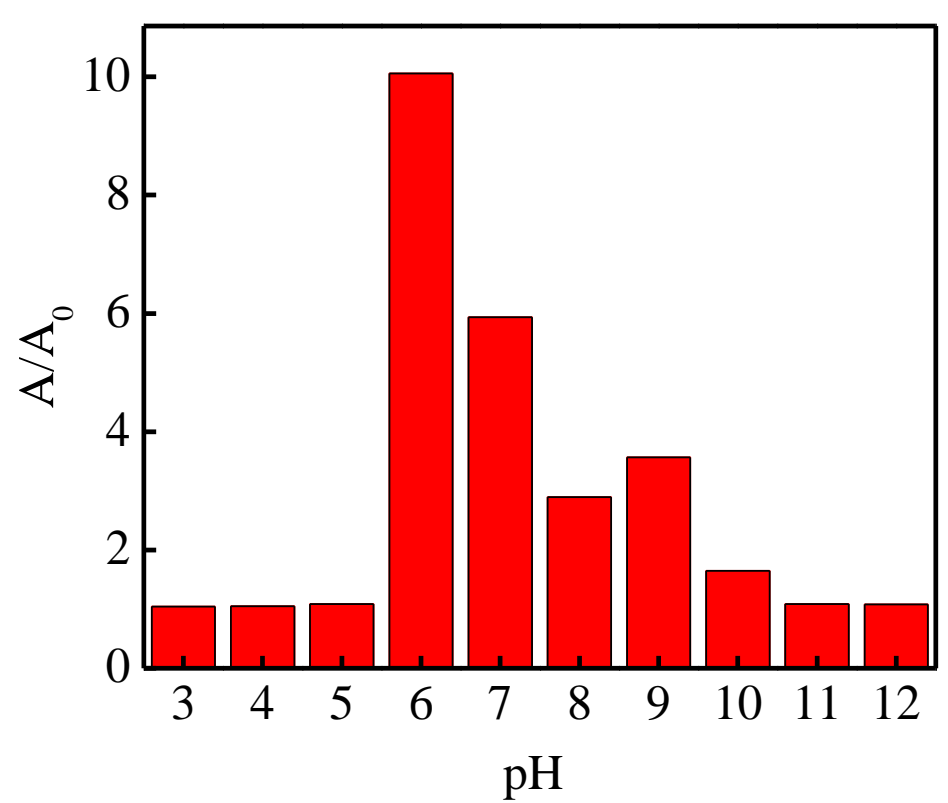

Figure 6. Absorbance alteration of DHB under different $\mathrm{pH}$ conditions after the addition of $\mathrm{Cu}^{2+}$ 
1 charge neutrality and fully coordinated ligand were responsible for charge balancing of the $\mathrm{Cu}-$

2 center.

\section{3.4. Effect of pH}

4 The UV-vis scans were logged for DHB before and after the addition of $\mathrm{Cu}^{2+}$. Figure 6 illustrates

5 the results of the $\mathrm{pH}$ studies

6 conducted for the sensor. It is

7 evident that the probe exhibited

8 excellent performance in the $\mathrm{pH}$

9 range 6-7, which is also

10 physiologically relevant. The

11 sensing behaviour of the probe

12 enhanced as the $\mathrm{pH}$ of the

13 system increased towards the

14 neutral conditions. The

15 protonation of $\mathrm{N}$ of the

16 azomethnic linkage at extreme

17 acidic conditions and the

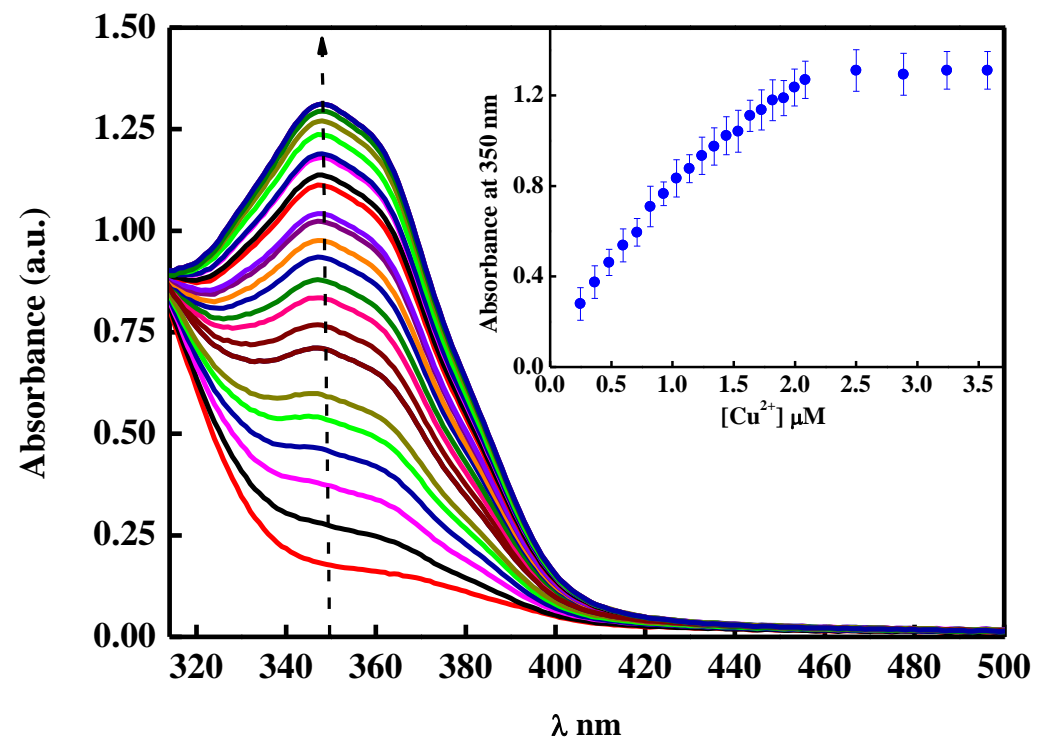

Figure 7. UV-vis absorption spectral changes of DHB $(10 \mu \mathrm{M})$ after addition of different $\mathrm{Cu}^{2+}$ concentrations. Inset: Absorbance at $350 \mathrm{~nm}$ v/s $\mathrm{Cu}^{2+}$ concentrations

formation of hydroxides at extreme basic conditions were responsible for the lower sensitivity of DHB at extreme pH i.e. 3-5 or 10-12. This broad range ensures a supreme performance of the sensor in close to the neutral condition, thereby making it applicable to a wide range of aqueous samples.

\subsection{Titration Studies}

After the analysis of the effect of $\mathrm{pH}$ on the sensing procedure, the absorption changes of DHB with increasing $\mathrm{Cu}^{2+}$ concentration were observed (figure 7). A welldefined blue shift $(\Delta \lambda \sim 15 \mathrm{~nm})$ was observed on successive addition of the analyte i.e. $\mathrm{Cu}^{2+}$. The selectivity of DHB particularly for $\mathrm{Cu}^{2+}$ can be

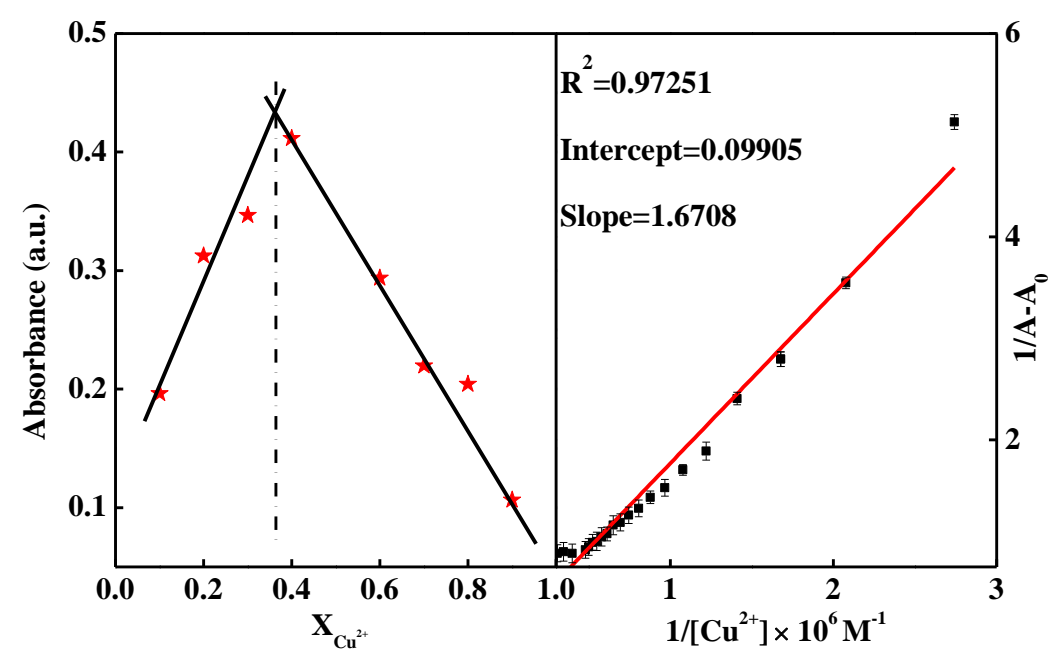

Figure 8 (a) Job's plot for the stoichiometric ratio of the complexation product between $\mathrm{DHB}$ and $\mathrm{Cu}^{2+}$ under invariant total concentration of $\mathrm{DHB}$ and $\mathrm{Cu}^{2+}$ (b) Benesi-Hildebrand plot for the estimation of binding constant 
attributed to ICT. The excitation by light causes ICT from an electron donor (heteroatoms) to electron acceptor (aromatic ring). The binding of $\mathrm{Cu}^{2+}$ to nitrogen and oxygen in conjugation with aromatic ring originated the blue shift in UV-vis spectra [42]. Nonetheless, the contribution of the paramagnetic effects of $\mathrm{Cu}^{2+}$ to these optical changes is also a possibility and cannot be ruled out. Likewise, the $\mathrm{d}-\mathrm{d}$ and $\mathrm{f}-\mathrm{f}$ transitions are weakly allowed because of the Laporte rules. Another evidence of the complexation was the HRMS spectrum (Figure S7) of the $\mathrm{Cu}^{2+}$ complex of DHB which clearly showed a peak at $\mathrm{m} / \mathrm{z}=634.09$.

As evident from the single-crystal X-ray analysis, a 1:2 binding stoichiometry was observed between $\mathrm{Cu}^{2+}$ and DHB (Figure 5). The plot of the absorbance versus the concentration of $\mathrm{Cu}^{2+}$ displayed a linear region from $0.24 \mu \mathrm{M}$ to $2.00 \mu \mathrm{M}$. The limit of detection (LOD) as calculated by $3 \sigma$ criterion [43] came out to be $0.156 \mu \mathrm{M}$. To further investigate the binding constant and validate the stoichiometry of binding between DHB and $\mathrm{Cu}^{2+}$, the results of the Benesi-Hildebrand [44] and Job's plot $[45,46]$ were examined. The association constant and binding ratio were evaluated using the Benesi-Hildebrand equation (1)

$\frac{1}{A-A_{0}}=\frac{1}{K\left(A_{\max }-A_{0}\right)\left[C u^{2+}\right]^{1}}+\frac{1}{A_{\max }-A_{0}}$

'The linearity of the Benesi-Hildebrand plot indicated the presence of one metal centre in the complex (Figure 8b). The Job's plot of the absorptions of the varied mole fraction of $\mathrm{Cu}^{2+}$ by keeping the total concentration of DHB \& $\mathrm{Cu}^{2+}$ invariant was analyzed. As expected, the maximum at a 0.33-mole fraction of the Job's plot (Figure 8a) further validated 1:2 stoichiometric ratio of the complex formed between $\mathrm{Cu}^{2+}$ and DHB. The comparison of the solvent system, selectivity, detection limit, and fabrication process was made with the previously reported sensors (Table S3). The previously reported probes display shortcomings in comparison to the proposed probe in terms of the solvent system and detection limit.

\subsection{Interference Studies}

To investigate the selectivity of the probe DHB towards $\mathrm{Cu}^{2+}$, competitive studies were done with other metal ions $\mathrm{Ag}^{+}, \mathrm{Al}^{3+}, \mathrm{Ba}^{2+}, \mathrm{Ca}^{2+}, \mathrm{Cd}^{2+}, \mathrm{Ce}^{3+}, \mathrm{Co}^{2+}, \mathrm{Cr}^{2+}, \mathrm{Fe}^{2+}, \mathrm{K}^{+}, \mathrm{Mg}^{2+}, \mathrm{Na}^{+}, \mathrm{Ni}^{2+}$, $\mathrm{Pb}^{2+}, \mathrm{Zn}^{2+}, \mathrm{Hg}^{2+}, \mathrm{Mn}^{2+}$ and $\mathrm{Fe}^{3+}$ in the presence of $\mathrm{Cu}^{2+}(10 \mu \mathrm{M})$. To carry out the competitive experiments, a number of DHB solutions containing equimolar metal ion species after addition of $\mathrm{Cu}^{2+}$ were scanned for absorption. The competitive studies were conducted for $50 \mu \mathrm{M}$ (Figure 9), $100 \mu \mathrm{M}$ and $150 \mu \mathrm{M}$ of competitive ions (Figure S2). As clear from figure 9, no significant interference was observed for any cationic species $[40,47,48]$. This capability of the probe DHB 
1 to exclusively sense the $\mathrm{Cu}^{2+}$ even

2 with the simultaneous presence of

3 other metal ions entitles its

4 suitability as a useful copper

5 sensor.

6

7

8

9

\subsection{Application on real} samples

To investigate the real-time applicability of the chemosensor DHB, samples collected from different water sources were analyzed. Each of the water sample collected was spiked with a known amount of $\mathrm{Cu}^{2+}$ and was analyzed for its tendency to sense $\mathrm{Cu}^{2+}$. The amount of $\mathrm{Cu}^{2+}$ in each of the sample was calculated using the calibration curve (Figure 7). Figure 10 shows the visible colour transitions observed in all the water samples and confirmed the ability of the sensor to sense $\mathrm{Cu}^{2+}$. The

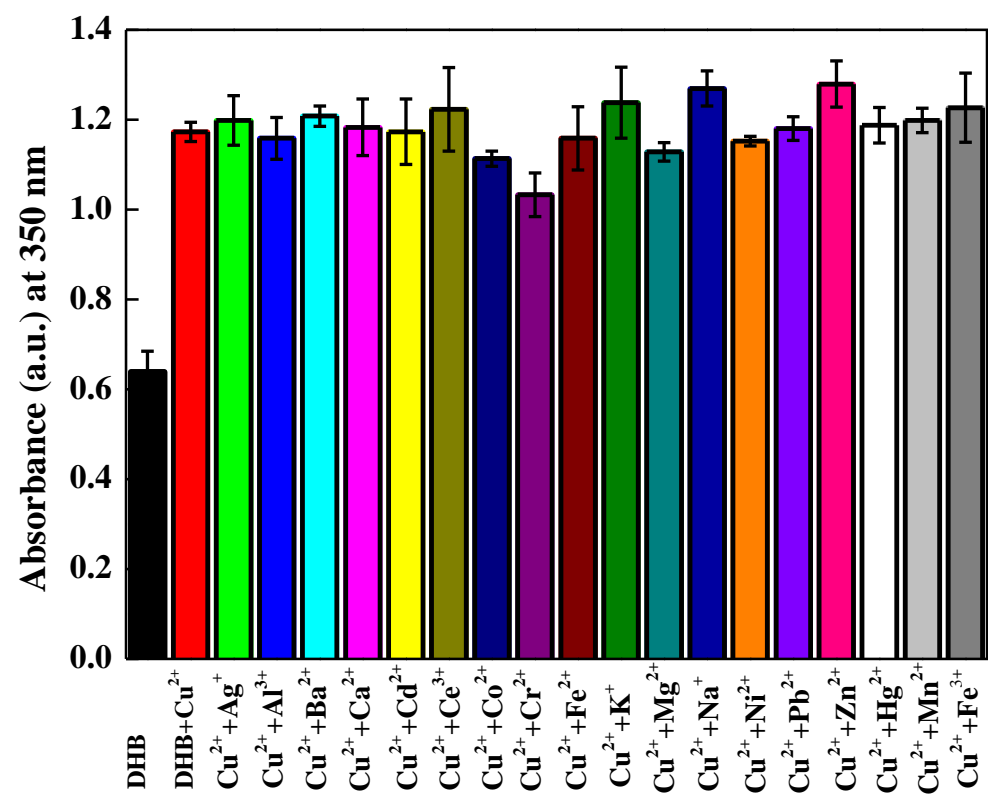

Figure 9. Interference studies for the selectivity of the chemosensor DHB towards $\mathrm{Cu}^{2+}(10 \mu \mathrm{M})$ in the co-existence of other cationic species $(50 \mu \mathrm{M})$

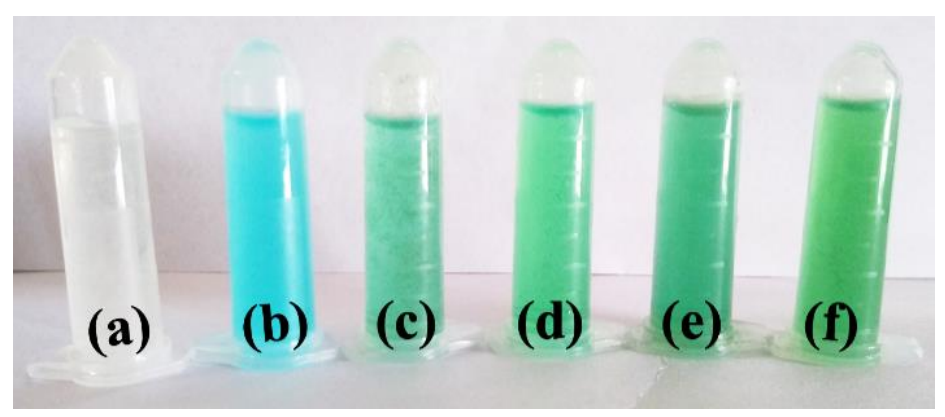

Figure 10. Colour of (a) DHB only (b) $\mathrm{Cu}^{2+}$ only and change in colour of $\mathrm{DHB}$ after addition of $\mathrm{Cu}^{2+}$ solution (c) in sea water (d) distilled water (e) river water and (f) drinking water recoveries and LOD values obtained for each of the water samples (Figure S3) are listed in Table 2.

Table 2. Estimation of $\mathrm{Cu}^{2+}$ in different water samples collected from various sources

\begin{tabular}{|l|l|l|l|l|}
\hline Sample & Added $(\boldsymbol{\mu M})$ & Found $(\boldsymbol{\mu M})$ & $\begin{array}{l}\text { Recovery \% } \\
(\mathbf{m e a n} \pm \text { S.D) }\end{array}$ & LOD $(\boldsymbol{\mu M})$ \\
\hline \multirow{3}{*}{ Sea Water } & 0.25 & 0.247 & $98.8 \pm 0.10$ & \multirow{2}{*}{0.589} \\
\cline { 2 - 4 } & 1.53 & 1.538 & $100.5 \pm 0.05$ & \\
\hline
\end{tabular}




\begin{tabular}{|l|l|l|l|l|}
\hline & 2.50 & 2.494 & $99.76 \pm 0.11$ & \\
\hline \multirow{5}{*}{ Drinking Water } & 0.25 & 0.256 & $102.4 \pm 0.10$ & \multirow{2}{*}{0.580} \\
\cline { 2 - 4 } & 1.53 & 1.546 & $101.0 \pm 0.08$ & \\
\cline { 2 - 4 } & 2.50 & 2.482 & $99.28 \pm 0.05$ & \multirow{2}{*}{0.513} \\
\hline \multirow{5}{*}{ River Water } & 0.25 & 0.246 & $98.4 \pm 0.09$ & \\
\cline { 2 - 4 } & 1.53 & 1.539 & $100.5 \pm 0.04$ & \multirow{2}{*}{0.492} \\
\cline { 2 - 4 } & 2.50 & 2.52 & $100.8 \pm 0.10$ & \\
\cline { 2 - 4 } & 0.25 & 0.258 & $103.2 \pm 0.10$ & \\
\cline { 2 - 4 } & 1.53 & 1.535 & $99.1 \pm 0.10$ & \\
\cline { 2 - 4 } & 2.50 & 2.479 & & \\
\end{tabular}

\section{3.8. Response time and Stability}

2 To determine the efficacy of the probe for real-time analysis, the response time of the DHB to tag the target and stability of both DHB and the complex formed after the interaction of the analyte with probe plays a fundamental role. The response time is the time interval after which a saturated absorbance plot is achieved in the presence of a fixed amount of $\mathrm{Cu}^{2+}$. Application of the DHB to the samples prompted an instant colour change to green following $\mathrm{Cu}^{2+}$ addition. Since it took $\sim 3$ minutes to scan and record the UV-vis spectrum, the response time can be stated to be less than $3 \mathrm{~min}$. Figure S4 displays the plot of absorbance at $350 \mathrm{~nm}$ versus time. The stability of DHB and the $\mathrm{Cu}(\mathrm{II})$-DHB complex was evaluated by recording the absorbance for a significant time period. The absorption spectra of the DHB and $\mathrm{Cu}$ (II)-DHB for $3.5 \mathrm{~h}$ at the interval of 15 min were logged. The UV-vis spectrum was recorded after 6 months also. The absence of any significant change in UV-vis absorbance specified the stability of both the DHB (Figure S5) and $\mathrm{Cu}(\mathrm{II})$-DHB complex further substantiating the field application of this sensor towards copper detection (Figure S6).

\subsection{DFT Study}

The geometry optimization for $\mathrm{Cu}(\mathrm{II})$-DHB complex was done at the mixed level of theory using Gaussian 09 [49] with 6-31G (d,p) and LANL2DZ, whereas for the free ligand (DHB) 6-31G (d,p) basis set was employed (Figure 11). The absence of imaginary frequency for the optimized structures designated the local minima of their geometries. 
3 Atomic charge distribution between donor sites and acceptor sites were estimated by natural population analysis (NPA) in the gas phase. By comparing the atomic charges, it was observed that the electron density on $\mathrm{Cu}(\mathrm{II})$ cation increased after complexation. For instance, before complexation, the formal charge on $\mathrm{Cu}$ (II) was +2 , whereas the charge on $\mathrm{Cu}$ in $(\mathrm{Cu}$ (II)-DHB) is +0.934 . This clearly indicated transfer of negative charges from the donor atoms of the $\mathrm{DHB}$ to the $\mathrm{Cu}(\mathrm{II})$ ion during complex formation.

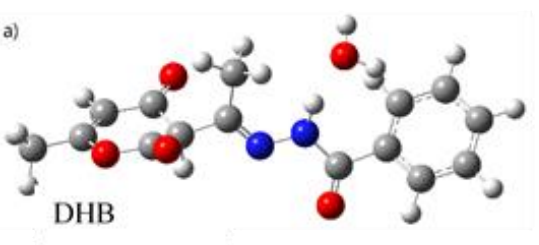

$\mathrm{Cu}(\mathrm{II})-\mathrm{DHB}$

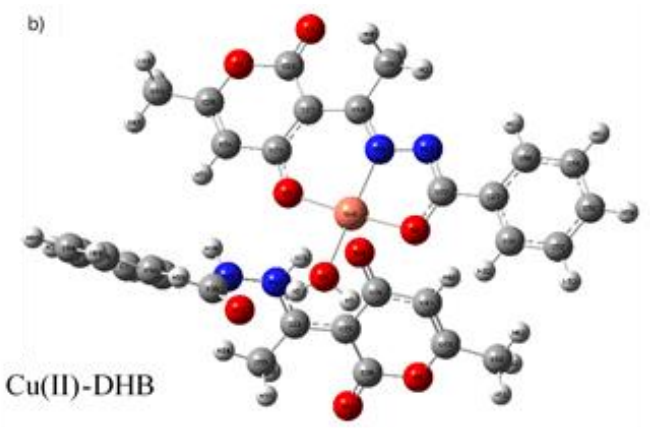

Figure 11. DFT optimized geometry of the a) DHB ligand b) $\mathrm{Cu}(\mathrm{II})$-DHB complex

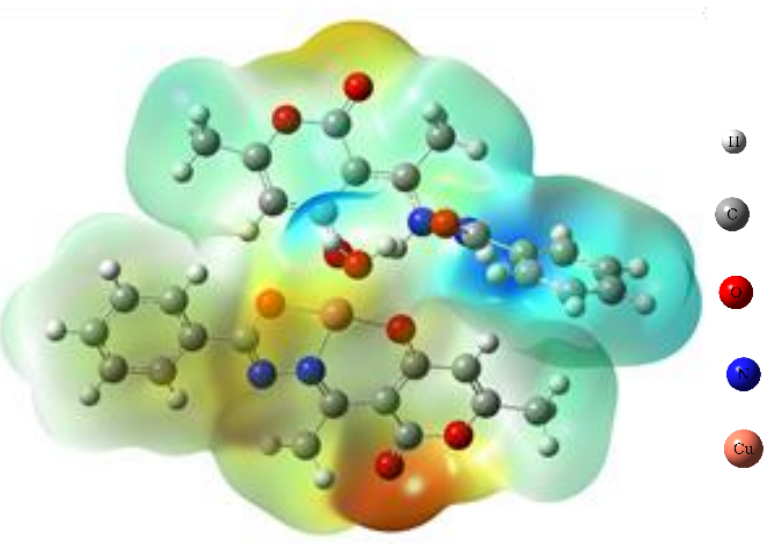

Figure 12. Molecular electrostatic potential surface of $\mathrm{Cu}(\mathrm{II})$-DHB complex. The electrophilic regions are represented by red, nucleophilic by blue and neutral electrostatic potential by green

Molecular Electrostatic Potential (MEP) is an important tool to analyze the electrophilic and nucleophilic sites which facilitate recognition of hydrogen-bonding interactions and physical properties like electronegativity, chemical reactivity and dipole moment. The MEP surface was mapped on the optimized geometry of the complex (Figure 12). The electrophilic regions were observed to be mainly concentrated on the carbonyl group of the amide (represented by red color). On the other hand, the conjugated carbonyl group and hydrogens of the aromatic ring represented sites of positive electron density. The energy gap of highest occupied molecular orbital (HOMO) and lowest unoccupied molecular orbital (LUMO) reflect several characteristic attributes of a molecule [50-52]. For instance, a molecule having a small frontier orbital gap is associated with high polarizability and generally exhibit high chemical reactivity and low kinetic stability. The energies associated with HOMO and LUMO for $\mathrm{Cu}$ (II)-DHB complex were calculated using the B3LYP method and 6-31G (d,p)/LANL2DZ basis sets in the gas phase. The HOMO of $\alpha$-and $\beta$-orbitals were observed to be mainly concentrated around amide of the DHB 
1 ligand directly bonded to the $\mathrm{Cu}^{2+}$. The LUMO of $\alpha$-orbitals concentrated on the hydrazone

2 functionality of the bonded DHB ligand, whereas LUMO of $\beta$-orbitals was on the conjugated 3 carbonyl group of the free DHB ligand. 3D plots for frontier molecular orbitals (FMO) along 4 with the gap associated with them are illustrated in figure 13. Since HOMO represents an outer

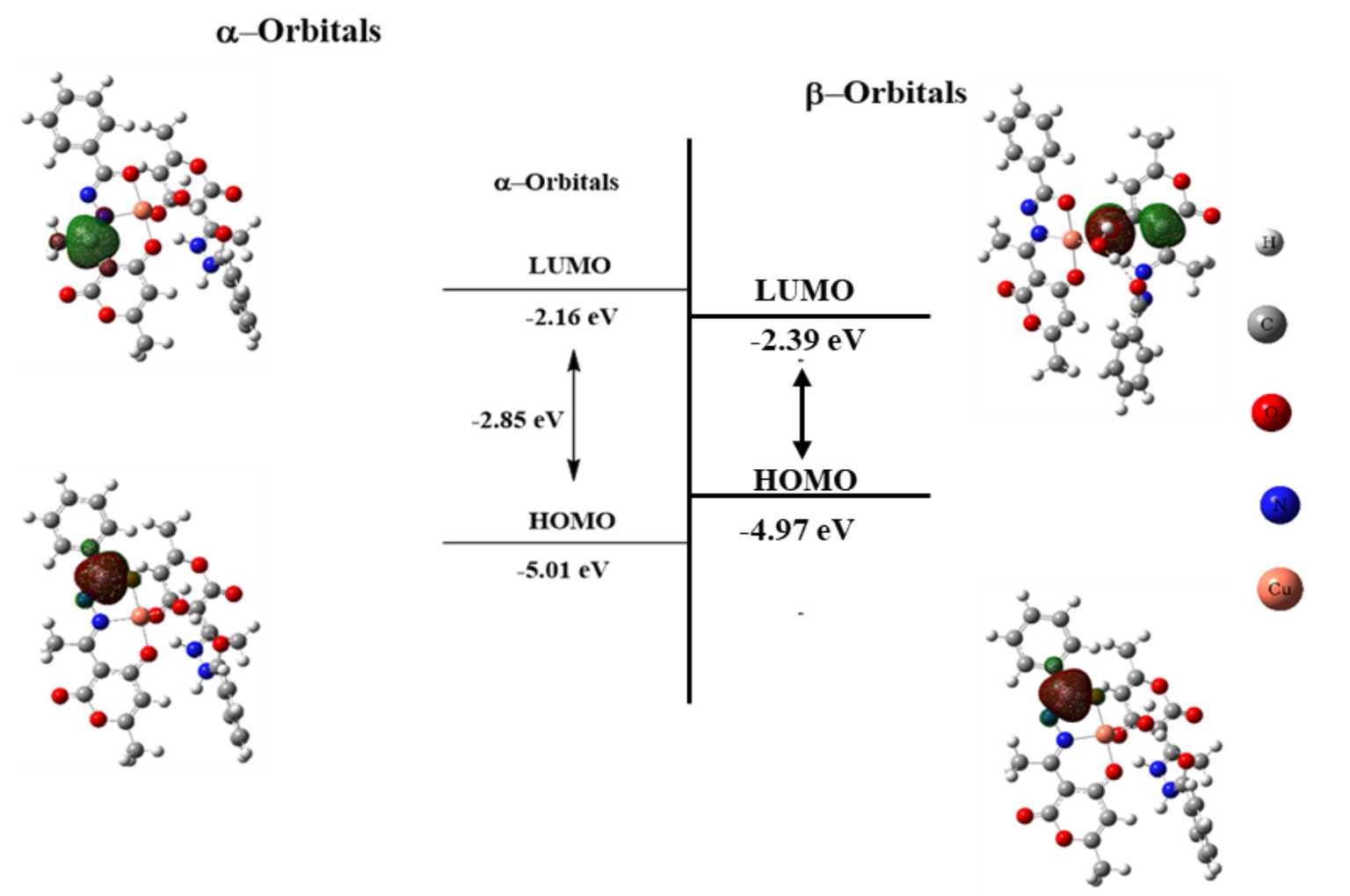

Figure 13. HOMO-LUMO orbital surfaces and energy gap for $\mathrm{Cu}$ (II)-DHB complex. Red indicates occupied orbital and green indicates unoccupied orbitals

5 orbital containing electrons, it acts as an electron donor and hence ionization potential (I) is 6 directly related to the energy of the HOMO. Similarly, LUMO can act as an electron acceptor, 7 therefore, the LUMO energy is directly related to an electron affinity (A). Therefore, both I and 8 A of $\mathrm{Cu}(\mathrm{II})$-DHB complex were calculated by means of Koopmans theorem with $\mathrm{E}_{\mathrm{HOMO}}$ and 9 Elumo values as $\mathbf{I}=-\mathrm{E}_{\text {Hоmo }}$ and $\mathbf{A}=-\mathrm{E}_{\mathrm{LUMO}}$. A measure of the confrontation to change in electron distribution of a moiety can be quantified using chemical hardness $(\eta)$ of a molecule which in turn is related to the stability and reactivity of a system [53]. The more the value of chemical hardness, lesser is the chemical reactivity and hence greater chemical stability. The stability and reactivity associated with a molecular system can also be characterized using well-known global reactivity descriptors such as electronic chemical potential $(\mu)$, global electrophilicity index $(\omega)$ and softness (S). All these values are calculated as shown in table 3. 


\begin{tabular}{cccccccc}
\hline Compound & $\begin{array}{l}\text { HOMO } \\
(\mathbf{e V})\end{array}$ & $\begin{array}{l}\text { LUMO } \\
(\mathbf{e V})\end{array}$ & $\begin{array}{l}\text { Chemical } \\
\text { hardness } \\
\eta=1 / 2(\mathrm{I}-\mathrm{A})\end{array}$ & $\begin{array}{l}\text { Chemical } \\
\text { potential } \\
\mu=-1 / 2(\mathrm{I}+\mathrm{A})\end{array}$ & $\begin{array}{l}\text { Chemical } \\
\text { softness } \\
\mathrm{S}=1 / 2 \eta\end{array}$ & $\begin{array}{l}\text { Electronega } \\
\text { tivity } \\
\chi=-\mu\end{array}$ & $\begin{array}{l}\text { Electrophilicity } \\
\text { index } \\
\omega=\mu^{2} / 2 \eta\end{array}$ \\
\hline Cu-DHB & -4.99 & -2.28 & 1.36 & -3.64 & 0.68 & 3.64 & 4.87 \\
\hline
\end{tabular}

3

4

\section{Hirshfeld Surface Analysis}

The mapping of the Hirshfeld surface in a crystal molecule demonstrates three-dimensional electron density, which gives insight into the strong intermolecular interactions surrounding the molecule in a qualitative and quantitative manner. The Hirshfeld surface analysis was performed by Crystal Explorer3.1as shown in Figure 14 [54].
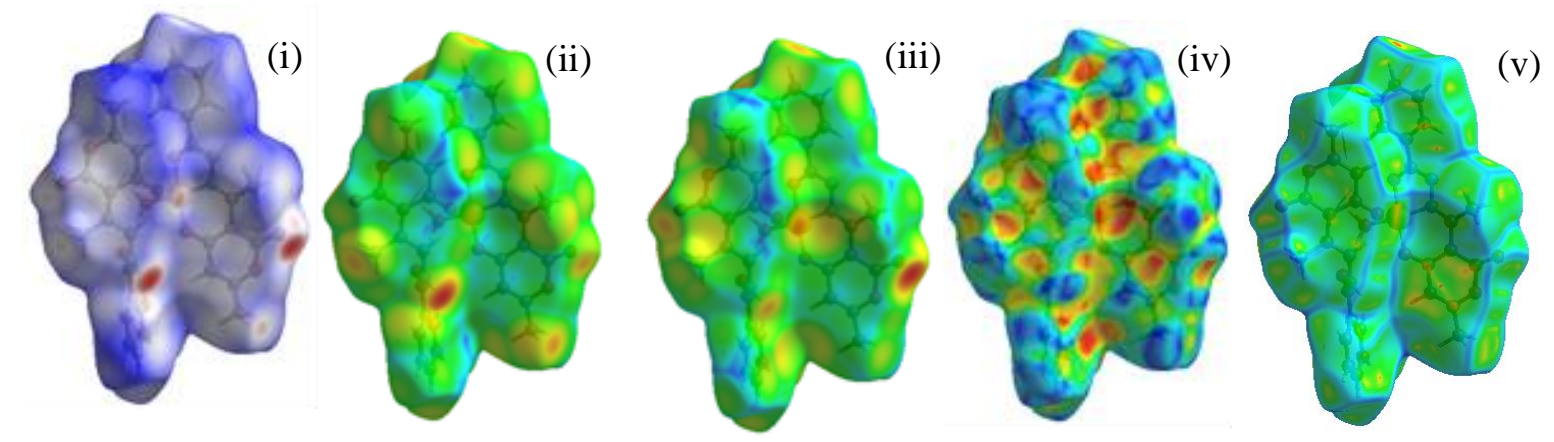

Figure 14. Hirshfeld surfaces mapped over (i) $d_{n o r m}$; (ii) $d_{i}$; (iii) $d_{e}$; (iv) shape index and (v) curvedness for $\mathrm{Cu}(\mathrm{II})$-DHB complex

In the surface analysis, $d_{e}$ represents the distance of internal atoms to the nearest surface points. However, $d_{i}$ represents the distance of exterior atoms to the nearest points on the surface [55].

The Hirshfeld surfaces of the Cu(II)-DHB complex were mapped over $d_{n o r m}, d_{i}$ and $d_{e}$ in a transparent manner so that the molecular structure can be visualized around which these properties were calculated (Figure 14).

The appearance of large circular deep-red spots visible on the surface mapped over $\mathrm{d}_{\text {norm }}$ indicated close contacts particularly hydrogen bonds, however diminutive spots on the surface designated contacts other than hydrogen bonding which are generally weaker and longer (Figure $15 \mathrm{~A}, \mathrm{~B})$.

The 2D fingerprint plots for the $\mathrm{Cu}$ (II)-DHB complex were also mapped for the quantification of intermolecular interactions which were further disintegrated to explore per atom interactions present within the structure are shown in figure 15. A noteworthy molecular interaction of $\mathrm{O}-\mathrm{H}$ type was reflected which contributed $22.8 \%$ of the total surface area of the 
1 complex (Figure $15 \mathrm{C}-\mathrm{D})$. It clearly points out the role of hydrogen bonding in the formation and

2 stability of crystal. Also, C-H type contributed 14\% of the Hirshfeld surface which originated 3 mainly due to the electrostatic interactions between carbonyl carbon $(-\mathbf{C}=\mathrm{O})$ of ester and 4 hydrogen attached to the nitrogen of amide(-CONH-) as shown in figure $15 \mathrm{E}$.

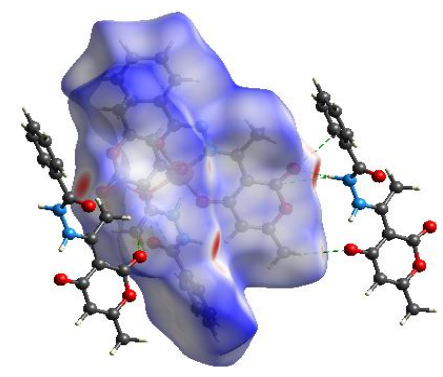

A

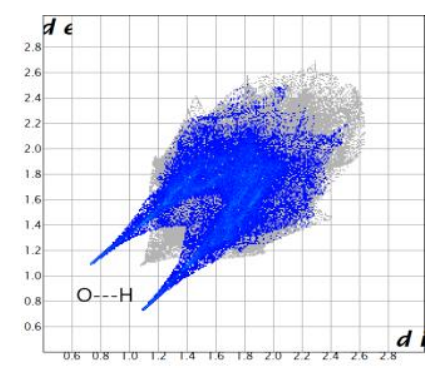

D

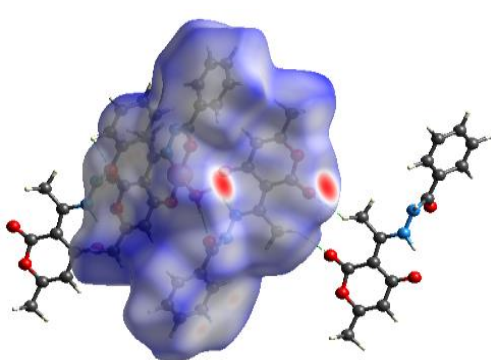

B

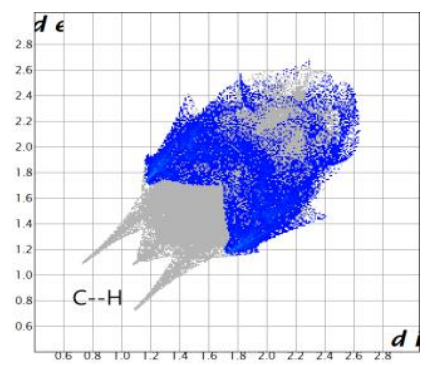

E

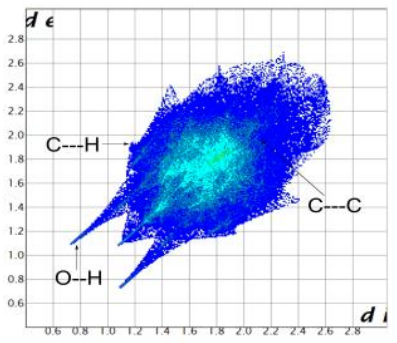

C

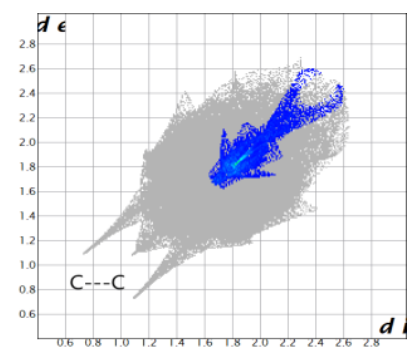

$\mathbf{F}$

Figure 15. A and $B$ represent views of the dnorm Hirshfeld surfaces of $\mathrm{Cu}$ (II)-DHB complex in two orientations. $\mathrm{C}$ represents close intermolecular contacts between all the atoms. D, E, and $\mathrm{F}$ represent close intermolecular contacts between $\mathrm{O}-\mathrm{H}, \mathrm{C}-\mathrm{H}$, and C-C respectively

The calculations revealed that interactions of the C-C type contributed 5.9\% mainly arising due to $\pi--\pi$ interactions, whereas interactions arising due to $\mathrm{N}$ atom were scarce as their contribution came to be only $1.8 \%$ of the total intermolecular interactions in the crystal structure figure $15 \mathrm{~F}$.

\section{Conclusions}

In summary, a selective and sensitive colorimetric chemosensor is synthesized and characterized which can detect the $\mathrm{Cu}^{2+}$ in an aqueous medium by producing a visible color change. The proposed chemosensor has many advantages in terms of its solubility in near aqueous medium; its selective, sensitive and instantaneous response for $\mathrm{Cu}^{2+}$ in aqueous medium; high efficiency in physiological $\mathrm{pH}$ range, its applicability to wide range of field samples of different origins; its LOD value of $0.156 \mu \mathrm{M}$ and its ability to sense $\mathrm{Cu}^{2+}$ even with the co-existence of other ionic species. The cost-effectiveness of the simple synthesis procedure and the excellent performance of the chemosensor makes it appropriate for field investigations 
and real-time analysis. The overlapping of theoretical and experimental conclusions validated the proposed mechanism. The single-crystal X-ray analysis, Density Functional theory calculations, the Benesi-Hildebrand plot and the Job's plot confirmed the 1:2 stoichiometric binding between $\mathrm{Cu}^{2+}$ and DHB. The outstanding performance, easy synthesis, and the synchronized crystal structure results extend its usefulness in the field of optical sensing.

\section{Acknowledgements}

The authors are thankful to DST, Government of India for PURSE Grant (II) and FIST (II) for Single-crystal facility at the Department of Chemistry, Panjab University, Chandigarh. Vikram Saini acknowledges grant support from Innovative Young Biotechnologist Award (BT/11/IYBA/2018/01) and DST-SERB core grant (CRG/2018/004510). Vaneet Saini recognizes DST for DST-Inspire grant (DST/INSPIRE/04/2017/002529). The authors are also thankful to Sophisticated and Analytical Instrumentation Facility (SAIF)/Central Instrumentation Laboratory (CIL), Panjab University, Chandigarh, India for providing access to necessary instrumentation facilities.

\section{References}

[1] J. Anastassopoulou, T. Theophanides, The Role of Metal Ions in Biological Systems and Medicine, Bioinorg. Chem. (2013) 209-218.

[2] G. X. Liang, H. Y. Liu, J. R. Zhang, J. J. Zhu, Ultrasensitive $\mathrm{Cu}^{2+}$ sensing by near-infraredemitting CdSeTe alloyed quantum dots, Talanta 80 (2010) 2172-2176.

[3] T. Theophanides, Metal Ions in Biological Systems, Int. J. Quantum Chem. 26 (1984) 933-941.

[4] D. Maity, T. Govindaraju, Highly selective colorimetric chemosensor for $\mathrm{Co}^{2+}$, Inorg. Chem. 50 (2011) 11282-11284.

[5] Z. Liu, X. Jia, P. Bian, Z. Ma, A simple and novel system for colorimetric detection of cobalt ions, Analyst. 139 (2014) 585-588.

[6] K. Kaur, S. Chaudhary, S. Singh, S. K. Mehta, Highly selective probe based on imine linkage for $\mathrm{Zn}^{2+}$ and $\mathrm{HSO}_{3}{ }^{-}$in mixed aqueous media, J. Lumin. 160 (2015) 282-288.

[7] Y. Wang, L. Wang, L. L. Shi, Z. Bin Shang, Z. Zhang, W. J. Jin, Colorimetric and fluorescence sensing of $\mathrm{Cu}^{2+}$ in water using 1,8 -dihydroxyanthraquinone- $\beta$-cyclodextrin complex with the assistance of ammonia, Talanta. 94 (2012) 172-177.

[8] B. Kaur, N. Kaur, S. Kumar, Colorimetric metal ion sensors - A comprehensive review of the years 2011-2016, Coord. Chem. Rev. 358 (2018) 13-69.

[9] D. Wu, A. C. Sedgwick, T. Gunnlaugsson, E. U. Akkaya, J. Yoon, T. D. James, Fluorescent chemosensors: the past, present and future, Chem. Soc. Rev. 46 (2017) 7105- 
7123.

[10] B. Wang, E. V. Anslyn, A Chemosensors Principles, Strategies and Applications, Wiley (2011), ISBN: 978-0-470-59206-9.

[11] X. Tang, J. Han, Y. Wang, L. Ni, X. Bao, L. Wang, W. Zhang, A multifunctional Schiff base as a fluorescence sensor for $\mathrm{Fe}^{3+}$ and $\mathrm{Zn}^{2+}$ ions, and a colorimetric sensor for $\mathrm{Cu}^{2+}$ and applications, Spectrochim. Acta - Part A Mol. Biomol. Spectrosc. 173 (2017) 721726.

[12] R. Kataria, K. Sethuraman, D. Vashisht, A. Vashisht S. K. Mehta, A. Gupta, Colorimetric detection of mercury ions based on anti-aggregartion of gold nanoparticles using 3,5dimethyl-1-thiocarboxamidepyrazole, Microchem. J. 148 (2019) 299-305.

[13] R. Kataria, R. Patra, H. K. Sharma, G. Singh, G. Kumar, S. Kumar, Spectrophotometric determination of Tin (II) with 6-Chloro-2-(2'-furyl)-3-Hydroxy-\&-Methyl-4-Oxo-4H-1Benzopyran and its solution state structure study by DFT, Sensor Lett. 15 (2017) 25-31.

[14] A. M. Abu-Dief, I. M. A. Mohamed, A review on versatile applications of transition metal complexes incorporating Schiff bases, Beni-Suef Univ. J. Basic Appl. Sci. 4 (2015) 119133.

[15] A. K. Manna, K. Rout, S. Chowdhury, G. K. Patra, A dual mode highly selective and sensitive Schiff base Chemosensor for fluorescent colorimetric detection of $\mathrm{Cu}^{2+}$, Photochem. Photobiol. Sci. 18 (2019) 1512.

[16] J. B. Chae, D. Yun, H. Lee, H. Lee, K. Kim, C. Kim, Highly Sensitive Dansyl-Based Chemosensor for Detection of $\mathrm{Cu}^{2+}$ in Aqueous Solution and Zebrafish, ACS Omega, 4 (2019) 12537-12543.

[17] D. H. Joo, J. S. Mok, G. H. Bae, S. E. Oh, J. H. Kang, C. Kim, Colorimetric Detection of $\mathrm{Cu}^{2+}$ and Fluorescent Detection of $\mathrm{PO}_{4}{ }^{3-}$ and $\mathrm{S}^{2-}$ by a Multifunctional Chemosensor, 56 (2017) 8339-8407.

[18] D. Udhayakumari, S. Naha, S. Velmathi, Colorimetric and fluorescent chemosensors for $\mathrm{Cu}^{2+}$. A comprehensive review from the years 2013-2015, Anal. Methods, 9 (2017) 552.

[19] N. Sainin, N. Prigyai, C. Wannasiri, V. Ervithyasuporn, S. Kiatkamjornwong, Green synthesis of fluorescent N, O-chelating hydrazine Schiff base for multi-analyte sensing in $\mathrm{Cu}^{2+} \mathrm{F}^{2}$ and $\mathrm{CN}^{-}$ions, J. Photochem. Photobiol A. Chem. 358 (2018) 215-225.

[20] H. Y. Kim, H. J. Lee, S. K. Chang, Reaction-based colorimetric signaling of $\mathrm{Cu}^{2+}$ ions by oxidative coupling of phenols with 4-aminoantipyrine, Talanta 132 (2015) 625-629.

[21] P. Kaur, D. Sareen, K. Singh, Selective colorimetric sensing of $\mathrm{Cu}^{2+}$ using triazolyl monoazo derivative, Talanta 83 (2011) 1695-1700.

[22] N. Wang, Y. Liu, Y. Li, Q. Liu, M. Xie, Fluorescent and colorimetric sensor for $\mathrm{Cu}^{2+}$ ion based on formaldehyde modified hyperbranched polyethylenimine capped gold nanoparticles, Sensors Actuators B Chem. 255 (2018) 78-86.

[23] Y. Jiao, L. Zhou, H. He, J. Yin, Q. Gao, J. Wei, C. Duan, X. Peng, A novel rhodamine Bbased "off-on" fluorescent sensor for selective recognition of copper (II) ions, Talanta. 184 (2018) 143-148. 
[24] R. Liu, Z. Chen, S. Wang, C. Qu, L. Chen, Z. Wang, Colorimetric sensing of copper (II) based on catalytic etching of gold nanoparticles, Talanta. 112 (2013) 37-42.

[25] J. Peng, G. Liu, D. Yuan, S. Feng, T. Zhou, A flow-batch manipulated Ag NPs based SPR sensor for colorimetric detection of copper ions $\left(\mathrm{Cu}^{2+}\right)$ in water samples, Talanta. 167 (2017) 310-316.

[26] S. C. Sahoo, R. Kataria, S. K. Mehta, Copper and its complexes: A pharmaceutical perspective in Chemical Drug Design (Ed. G. K. Gupta, V. Kumar), Berlin, Boston, De Gruyter (2016) 215-236.

[27] Y. Yang, S. Ma, Y. Zhang, J. Ru, X. Liu, H. Guo, A novel biphenyl-derived salicylhydrazone Schiff base fluorescent probes for identification of $\mathrm{Cu}^{2+}$ and application in living cells, Spectrochim. Acta Part A Mol. Biomol. Spectrosc. 199 (2018) 202-208.

[28] N. Mergu, M. Kim, Y. Son, A Coumarin-derived $\mathrm{Cu}^{2+}$-fluorescent chemosensor and its direct application in aqueous media, Spectrochim. Acta Part A Mol. Biomol. Spectrosc. 188 (2018) 571-580.

[29] M. N. Mahnashi, A. M. Mahmoud, S. A. Alkahtani, R. Ali, M. M. El-Wekhil, A novel imidazole derived colorimetric and fluorometric chemosensor for bifunctional detection of copper(II) and sulphide ions in environmental water samples, Spectrochim. Acta Part A Mol. Biomol. Spectrosc. 2019 doi.org/10.1016/j.saa.2019.117846.

[30] N. H. A. Razak, L. L. Tan, S. A. Hasbullah, L. Y. Heng, Reflectance chemosensor based on bis-thiourea derivative as ionophore for copper (II) ion detection, 2019, doi.org/10.1016/j.microc.2019.104460.

[31] A. Mohammadi, B. Khalili, A. S. Haghayegh, A novel chromene based colorimetric sensor for highly selective detection of copper ions: synthesis, optical properties and DFT calculations, Spectrochim. Acta Part A Mol. Biomol. Spectrosc. 222 (2019) 571-580.

[32] A. K. Manna, J. Mondal, K. Rout, G. K. Patra, A benzohydrazide based two in one $\mathrm{Ni}^{2+}$ / $\mathrm{Cu}^{2+}$ fluorescent colorimetric chemosensor and its applications in real sample analysis and molecular logic gate, Sens. Actuators B Chem. 275 (2018) 350-358.

[33] Rajnikant, Dinesh, Kamni, M. B. Deshmukh, S. D. Desai, B. S. Shinde, P. Kanwal, Synthesis and X-ray structure analysis of benzoic acid [1-(6-methyl-2,4-dioxo-3,4dihydro-2H-pyran-3-yl)-eth-(E)-ylidene]-hydrazide with a water molecule $\left(\mathrm{C}_{15} \mathrm{H}_{14} \mathrm{~N}_{2} \mathrm{O}_{4} \cdot \mathrm{H}_{2} \mathrm{O}\right)$, J. Chem. Crystallogr. 35 (2005) 357-360.

[34] O. V. Dolomanov, L. J. Bourhis, R. J. Gildea, J. A. K. Howard, H. Puschmann, OLEX2 : a complete structure solution, refinement and analysis program, J. Appl. Crystallogr. 42 (2009) 339-341.

[35] M .C. Burla, R. Caliandro, M. Camalli, B. Carrozzini, G. L. Cascarano, L. De Caro, C. Giacovazzo, G. Polidori, D. Siliqi, R. Spagna, IL MILIONE: A suite of computer programs for crystal structure solution of proteins, J. Appl. Crystallogr. 40 (2007) 609613.

[36] G. M. Sheldrick, Crystal structure refinement with SHELXL., Acta Crystallogr. Sect. C, Struct. Chem. 71 (2015) 3-8.

[37] D. Vashisht, K. Kaur, R. Jukaria, A. Vashisht, S. Sharma, S. K. Mehta, Colorimetric 
chemosensor based on coumarin skeleton for selective naked eye detection of cobalt (II) ion in near aqueous medium, Sensors Actuators B Chem. 280 (2019) 219-226.

[38] U. B. Patel, V. N. Mehta, M. A. Kumar, S. K. Kailasa, 4-Aminothiophenol functionalized gold nanoparticles as colorimetric sensors for the detection of cobalt using UV-Visible spectrometry, Res. Chem. Intermed. 39 (2013) 771-779.

[39] E. J. Song, J. Kang, G. R. You, G. J. Park, Y. Kim, S. J. Kim, C. Kim, R. G. Harrison, A single molecule that acts as a fluorescence sensor for zinc and cadmium and a colorimetric sensor for cobalt, Dalt. Trans. 42 (2013) 15514-15520.

[40] M. S. Hossain, C M Zakaria, Md. K. E. Zaham, B. Zaman, Synthesis, Spectral and Thermal Characterization of $\mathrm{Cu}(\mathrm{II})$ Complexes with Two New Schiff Base Ligand towards Potential Biological Application, Der Chem. Sin. 8 (2017) 380-392.

[41] A. K. Gupta, R. Pal, V. Beniwal, Novel Dehydroacetic Acid Based Hydrazone Schiff' S Base Metal Complexes of First Transition Series : Synthesis and Biological Evaluation Study, 4 (2015) 990-1008.

[42] Y. J. Zhang, X. P. He, M. Hu, Z. Li, X. X. Shi, G. R. Chen, Highly optically selective and electrochemically active chemosensor for copper (II) based on triazole-linked glucosyl anthraquinone, Dye. Pigment. 88 (2011) 391-395.

[43] S. A. Shahamirifard, M. Ghaedi, S. Hajati, A new silver (I) ions optical sensor based on nanoporous thin films of sol-gel by rose bengal dye, Sensors Actuators B Chem. 259 (2018) 20-29.

[44] O. Garcia-Beltran, N. Mena, L. C. Friedrich, J. C. Netto-Ferreira, V. Vargas, F. H. Quina, M.T. Nunez, B.K. Cassels, Design and synthesis of a new coumarin-based "turn-on" fluorescent probe selective for $\mathrm{Cu}^{2+}$, Tetrahedron Lett. 53 (2012) 5280-5283.

[45] W. Cao, X. J. Zheng, D. C. Fang, L. P. Jin, A highly selective and sensitive Zn (ii) complex-based chemosensor for sequential recognition of $\mathrm{Cu}$ (ii) and cyanide, Dalt. Trans. 43 (2014) 7298-7303.

[46] P. F. Hsu, Y. Chen, Synthesis of a Pyrene-Derived Schiff Base and Its Selective Fluorescent Enhancement by Zinc and Aluminum Ions, Int. J. Org. Chem. 08 (2018) 207228.

[47] S. Y. Kim, S.Y. Lee, J. M. Jung, M. S. Kim, C. Kim, Selective detection of $\mathrm{Cu}^{2+}$ and $\mathrm{S}^{2-}$ by a colorimetric chemosensor: Experimental and theoretical calculations, Inorganica Chim. Acta. 471 (2018) 709-717.

[48] K. Kaur, S. Chaudhary, S. Singh, S. K. Mehta, Imine modified ZnO nanoparticles: A luminescent chemodosimeter for $\mathrm{Al}^{3+}$ and $\mathrm{S}^{2-}$ ions based on ligand displacement reaction, New J. Chem. 39 (2015) 1773-1782.

[49] Gaussian 09, Revision D.01, M. J. Frisch, G. W. Trucks, H. B. Schlegel, G. E. Scuseria, M. A. Robb, J. R. Cheeseman, G. Scalmani, V. Barone, B. Mennucci, G. A. Petersson, H.Nakatsuji, M. Caricato, X. Li, H. P. Hratchian, A. F. Izmaylov, J. Bloino, G. Zheng, J. L. Sonnenberg, M. Hada, M. Ehara, K. Toyota, R. Fukuda, J. Hasegawa, M. Ishida, T. Nakajima, Y. Honda, O. Kitao, H. Nakai, T. Vreven, J. A. Montgomery, Jr., J. E. Peralta, F. Ogliaro, M. Bearpark, J. J. Heyd, E. Brothers, K. N. Kudin, V. N. Staroverov, R. 
Kobayashi, J. Normand, K. Raghavachari, A. Rendell, J. C. Burant, S. S. Iyengar, J. Tomasi, M. Cossi, N. Rega, J. M. Millam, M. Klene, J. E. Knox, J. B. Cross, V. Bakken, C. Adamo, J. Jaramillo, R. Gomperts, R. E. Stratmann, O. Yazyev, A. J. Austin, R. Cammi, C. Pomelli, J. W. Ochterski, R. L. Martin, K. Morokuma, V. G. Zakrzewski, G. A. Voth, P. Salvador, J. J. Dannenberg, S. Dapprich, A. D. Daniels, Ö. Farkas, J. B. Foresman, J. V.Ortiz, J. Cioslowski, and D. J. Fox, Gaussian, Inc., Wallingford CT, 2009.

[50] H. Chermette, Chemical reactivity indexes in density functional theory, J. Comput. Chem. 20 (1999) 129-154.

[51] R.G. Pearson, Chemical hardness and density functional theory, J. Chem. Sci. 117 (2005) 369-377.

[52] R.G. Parr, L.v. Szentpály, S. Liu, Electrophilicity index, J. Am. Chem. Soc. 121 (1999) 1922-1924.

[53] L. Pauling, The Nature of the Chemical Bond, Cornell university press Ithaca, NY 1960.

[54] S.Wolff, D. Grimwood, J. McKinnon, M. Turner, D. Jayatilaka, M.J.U.o.W.A. Spackman, Perth, Australia, Crystal explorer ver. 3.1, (2013).

[55] J. Dalal, N. Sinha, H. Yadav, B. Kumar, Structural, electrical, ferroelectric and mechanical properties with Hirshfeld surface analysis of novel NLO semiorganic sodium pnitrophenolate dihydrate piezoelectric single crystal, RSC Adv. 71 (2015) 57735-57748. 